\title{
Subtle thought disturbance in schizophrenia
}

Thought disorder, perhaps the most telling symptom of schizophrenia, presents itself in an infinite variety of ways. This ranges from unintelligible gibberish on the one hand to far more subtle disturbances on the other, disturbances which in other circumstances might be construed as examples of donnish games with twisted logic. Here is one that sticks in my memory.

Ian was a B.A. (London) failed. My belief is that he failed because of the onset of schizophrenia when he was an undergraduate and not, as his parents believed (his father was a professor of mathematics) that it was the shock of his failure that precipitated his mental illness. Ian was slightly built with the stoop commonly to be seen in more elderly academics. He had a beautifully modulated voice which seemed at odds with his peculiarly pedantic way of speaking. In manner he was essentially polite and all questions were answered with an accompanying courtly bow. The ravages of his illness had reduced him in fact to a caricature of what he might have been - a scholarly, if somewhat eccentric, university don.
One day, I was present in the Occupational Therapy Department where Ian, despite his intelligence and failed B.A., was seemingly content with his basket-makdng. Suddenly the air was rent by an ear-piercing shriek. Ian had smitten the girl alongside him, with whom he had been hitherto on excellent terms, with a wooden mallet. Admittedly he hadn't done much harm, but the department was temporarily in a state of uproar. Like some latter-day Sir Galahad I rushed to the scene of the assault, grabbed the mallet from the hand of the assailant, and in shocked surprise demanded, "Why did you do that?", or something equally banal. "Sir", he said with an air of outraged innocence, "I have read the rules of the hospital with the utmost care, and there is absolutely nothing against it".

Henry R. Rollin, Emeritus Consultant, Horton Hospital, Epsom

Other contributions to this column are welcome for consideration for publication. 